\title{
Decline in Gait Performance Detected by an Electronic Walkway System in 907 Older Adults of the Population-Based KORA-Age Study
}

\author{
Christine S. Autenrieth ${ }^{\mathrm{b}}$ Stefan Karrasch ${ }^{c}$ Margit Heier ${ }^{\mathrm{b}}$ Lukas Gorzelniak $^{\mathrm{b}, \mathrm{d}}$ \\ Karl-Heinz Ladwig ${ }^{b}$ Annette Peters ${ }^{b}$ Angela Döring ${ }^{a, b}$ \\ Institutes of ${ }^{a}$ Epidemiology I and ${ }^{b}$ Epidemiology II, Helmholtz Zentrum München, German Research Center \\ for Environmental Health, Neuherberg, and 'Institute and Outpatient Clinic for Occupational, Social and \\ Environmental Medicine, Ludwig-Maximilians-University, and ${ }^{\mathrm{d}}$ Institute of Medical Statistics and Epidemiology, \\ Klinikum rechts der Isar der TU München, Munich, Germany
}

\section{Key Words \\ Gait performance $\cdot$ Aging $\cdot$ Gait speed $\cdot$ Mobility aid users • Endoprosthesis $\cdot$ Population-based study}

\begin{abstract}
Background: Gait changes at older ages are a strong predictor of a decline in lower extremity functions. However, large population-based studies assessing gait parameters in various gait tasks are lacking. Objective: We investigated the relationship of age, the use of mobility aids and being fitted with an endoprosthesis with selected gait parameters, assessed in different walking tasks. Methods: In the population-based KORA-Age study, data from 907 men and women aged 65-91 years were obtained using the validated electronic walkway system GAITRite, which quantifies spatiotemporal gait parameters in the measurement range of a $488 \times 61 \mathrm{~cm}$ walkway mat. Participants completed three walking tasks at different speeds (normal, slow and fast) and a fourth walking task at normal speed with the additional task of counting backwards (dual-task walking). Ad-
\end{abstract}

ditionally, the impact of endoprostheses (hip or knee) and mobility aids was assessed. Results: The highest relative age-related decline for velocity was observed during dualtask walking (26.1\% for men and $23.4 \%$ for women) and for step length during fast walking ( 20.2 and $14.4 \%$ ) when comparing participants aged $<70$ years with those aged $\geq 85$ years. Weaker performances for velocity, cadence and step length were observed among women with knee or hip endoprostheses (fast walking speed) $(p<0.05)$. Across all walking tasks, significant differences between mobility aid users and nonusers were observed for velocity and step length among both men and women $(p<0.05)$. Conclusion: A decline in gait performance is most notable in fast speed and dual-task walking, in age-related endoprosthesis and mobility aid analyses. The marked relative decrease in gait parameters in these difficult gait tasks may be attributed to lacking resources for compensation among the elderly.

\section{KARGER}

Fax +4161306 1234

E-Mail karger@karger.ch

www.karger.com (c) 2012 S. Karger AG, Basel

0304-324X/13/0592-0165\$38.00/0

Accessible online at:

www.karger.com/ger
Christine S. Autenrieth, MSc, MA

Institute of Epidemiology II, Helmholtz Zentrum München German Research Center for Environmental Health

Ingolstädter Landstrasse 1, DE-85764 Neuherberg (Germany)

E-Mail christine.autenrieth@helmholtz-muenchen.de 


\section{Introduction}

The concept of successful aging and well-being consists of several dimensions including a high level of physical and cognitive functions $[1,2]$. In order to quantify physical performance in older adults, measurements of lower extremity movements, such as balance, timed upand-go test or gait parameters are applied $[3,4]$.

Gait patterns have been the subject of many studies in both children and adults in the past several years [5-9]. A variety of assessment tools have been used in previous studies, ranging from the time needed to complete a certain distance and visual monitoring with a camera [4] to a walkway that is able to record and assess a variety of gait patterns [10]. Previous work has shown that gait parameters recorded by the GAITRite electronic walkway system, such as velocity or step length, are subject to agerelated changes $[7,8]$. However, the majority of prior studies have mainly concentrated on analyzing specific gait parameters during normal walking, omitting other walking tasks, such as walking slowly, fast or dual-task walking. Yet, for everyday life, security in walking at different speeds is highly important for maintaining independence throughout aging.

At an older age, gait characteristics are likely to change in persons in need of mobility aids. Furthermore, in patients with endoprostheses, alterations of gait characteristics have been described [11-13]. However, data from large population-based studies regarding gait characteristics of older adults in need of mobility aids or fitted with endoprostheses are scarce.

The aim of the present study was to describe age- and sex-specific gait patterns, assessed by the GAITRite system, for different walking speeds or tasks in a large population-based study as well as separately analyzing individuals with endoprostheses (hip or knee) and persons who are using mobility aids for walking.

\section{Methods}

\section{Study Population}

Conducted in 2009, the KORA-Age project is a follow-up study of four MONICA/KORA Augsburg Surveys (1984/85, 1989/90, 1994/95 and 1999-2001). 4,127 persons aged 65-94 years involved in those surveys were interviewed via telephone and a randomly drawn sample of 1,079 cohort members additionally underwent an interview as well as extensive examinations in 2009. The time schedule and the sampling frame of the KORA-Age project have been described in detail elsewhere [14]. Gait analysis was not scheduled for persons who could not visit the KORA study center for examination $(\mathrm{n}=115)$. After exclusion of subjects with contra- indications ( $\mathrm{n}=15)$, technical problems $(\mathrm{n}=1)$, or refusals $(\mathrm{n}=3)$, 945 participants (482 men and 463 women) completed the quantitative gait assessment.

All subjects are currently followed within the frame of the Cooperative Health Research platform in the Region of Augsburg (KORA). The study was approved by the Ethics Committee of the 'Bayerische Landesärztekammer' (Medical Council of the Land Bavaria) and all subjects provided written informed consent.

\section{Assessment of Gait Parameters}

The GAITRite system (CIR Systems, Haverton, Pa., USA) is a validated electronic walkway $[15,16]$, capturing spatiotemporal gait parameters with sensor pads encapsulated within a $488 \times$ $61 \mathrm{~cm}$ walkway mat. These sensor pads are activated as the participant walks across the walkway and the footprints are immediately transferred to the connected monitor [17]. A detailed description of the selected gait parameters is provided by the manufacturer [18]. Following the guidelines of the European GAITRite Network group [10], participants were given extensive instructions by trained investigators before the examination. Four walking tasks were recorded: normal (usual pace), slow (strolling slowly without pausing), fast (walking at a good pace without starting to run) and dual-task walking (walking a normal speed with the additional task of counting backwards aloud in steps of 2 beginning with the number 50).

The starting and stopping points were precisely defined. In response to a clear 'start walking' signal, each person commenced with the respective walking task. After each trial, the subjects returned to the start position while data processing was ongoing. Before the actual measurement, every participant was allowed a trial. If necessary, gait-insecure and fall-prone persons were offered assistance.

\section{Covariables}

Height and weight were measured by trained medical staff, and body mass index (BMI) was calculated as weight in kilograms divided by height in meters squared. The mobility aid/walking-impaired group (henceforth referred to as mobility aid group) consisted of 47 persons in total and was further divided into the following subcategories (men, women): (1) one-sided cane/crutch (n $=11, \mathrm{n}=24) ;(2)$ two-sided cane/crutch $(\mathrm{n}=1, \mathrm{n}=2) ;(3)$ rollator $(\mathrm{n}$ $=2, \mathrm{n}=3)$; (4) walking impaired due to recent surgery $(\mathrm{n}=1, \mathrm{n}=$ 3). Self-reported leisure physical activity was dichotomized into the inactive $(<1 \mathrm{~h} /$ week) and the physically active $(\geq 1 \mathrm{~h} /$ week $)$ group. The score for the cognitive status was assessed by means of the Telephone Interview for Cognitive Status-modified (TICS-m) and included 21 items (name, orientation, concentration, memory, calculation, attention, language and conceptual skills). TICS-m scores were corrected for education years following Gallo et al. [19]: 2 points for $8-10$ years of education, no additional points for 11-15 years of education, and subtraction of 2 points for subjects with 16 or more years of education. We applied the cut-offs proposed in a validation study by Knopman et al. [20] to educationcorrected TICS-m scores: $\leq 31$ to separate subjects with mild cognitive impairment from subjects with normal cognition.

Information on arthritis, stroke, neurological disease and eye disease (cataract, glaucoma, macular degeneration and disorders of the retina) was obtained via telephone interview and dichotomized into yes and no. The presence of endoprostheses (hip, knee) was assessed during a standardized face-to-face interview at the KORA Study Center. 
Data Preparation

At the end of each calendar week, GAITRite data were checked and manually edited by trained staff. Foot falls outside the active surface area of the walkway and marks caused by mobility aids were removed. Foot prints which were not initially captured properly were reprocessed in the foot fall editor menu of the GAITRite software and then rerun for calculating spatiotemporal gait parameters. Missing walking speeds $(\mathrm{n}=9$ for slow, $\mathrm{n}=$ 15 for fast, $\mathrm{n}=22$ for dual-task walking) due to exhaustion of the participants or other reasons, as well as the use of walking aids were carefully documented. One subject's normal walk could not be used for further analyses due to technical problems. Quality control was performed regularly by comparing the data processed by two blinded staff members. After exclusion of persons with missing data on any of the covariables, 907 (454 men, 453 women) of the original 945 participants were included in our analyses.

\section{Statistical Analyses}

Collected gait variables of interest were calculated by the GAITRite system and analyzed with the statistical software package SAS 9.2 (SAS Institute, Inc., Cary, N.C., USA). Sex-specific characteristics of the study population are expressed as means and standard deviations for continuous variables. Categorical variables are expressed as absolute and relative frequencies. Univariate analyses were performed to describe the minimum and maximum values and some percentiles $(5,10,20,25,50,75,80$, $90,95)$ for the selected gait parameters (online supplementary table 1, www.karger.com/doi/10.1159/000342206).

According to the Shapiro-Wilk test, the normality of the distribution for the continuous gait parameters was not violated for the selected variables.

Linear regression models were performed to examine the sexspecific association between the five different 5 -year age groups and gait parameters after adjustment for height, weight, use of mobility aids, physical activity level, BMI, cognitive status, arthritis, stroke, neurological disease and eye disease. In addition, for each gait parameter, sex-specific means and 95\% confidence intervals (95\% CIs) were calculated separately in multivariable models for subjects fitted with endoprostheses (hip or knee) and those without as well as for subjects with mobility aids and those without. Confounders were simultaneously entered into the regression model. Regression models were calculated for each of the four walking conditions (normal, slow, fast and dual-task walking) individually. Tests were considered statistically significant with a two-sided $\mathrm{p}<0.05$.

\section{Results}

Sex-specific baseline information on age, anthropometric measurements and selected gait variables at normal speed is presented in table 1 . Women were less physically active and were more prone to arthritis, neurological and eye diseases than men. Women's performance in the TICS-m score was slightly better than men's. In general, men walked slightly faster (velocity) and totaled more steps per minute (cadence) than women at normal
Table 1. Baseline characteristics, means \pm SD and percentages

\begin{tabular}{|c|c|c|}
\hline & $\begin{array}{l}\text { Men } \\
(n=454)\end{array}$ & $\begin{array}{l}\text { Women } \\
(\mathrm{n}=453)\end{array}$ \\
\hline Age, years & $75.4 \pm 6.2$ & $75.7 \pm 6.4$ \\
\hline Height, $\mathrm{cm}$ & $171.0 \pm 6.9$ & $157.7 \pm 6.1$ \\
\hline Weight, kg & $83.5 \pm 12.7$ & $70.5 \pm 11.9$ \\
\hline BMI & $28.5 \pm 3.8$ & $28.3 \pm 4.6$ \\
\hline Leg length, cm & $91.2 \pm 4.5$ & $86.2 \pm 4.0$ \\
\hline Endoprosthesis, hip or knee, \% & 11.9 & 14.8 \\
\hline Mobility aid users, $\%$ & 3.3 & 7.1 \\
\hline Difficulties performing ADLs, \% & 17.2 & 32.5 \\
\hline Physically inactive, \% & 38.1 & 47.5 \\
\hline Impaired cognitive status, $\%$ & 13.2 & 10.4 \\
\hline Actual hypertension, \% & 74.5 & 75.3 \\
\hline Arthritis, \% & 17.1 & 19.2 \\
\hline Stroke, \% & 8.2 & 6.0 \\
\hline Neurological disease, $\%$ & 2.6 & 3.5 \\
\hline Eye disease, $\%$ & 37.4 & 50.6 \\
\hline Number of prescription medication & $3.5 \pm 2.8$ & $3.6 \pm 2.7$ \\
\hline Velocity, $\mathrm{cm} / \mathrm{s}^{1}$ & $109.4 \pm 24.0$ & $104.5 \pm 24.7$ \\
\hline Cadence, steps $/ \min ^{1}$ & $102.2 \pm 11.9$ & $107.5 \pm 14.0$ \\
\hline Step length, $\mathrm{cm}^{1}$ & $63.9 \pm 9.9$ & $57.8 \pm 8.6$ \\
\hline
\end{tabular}

$\mathrm{ADL}=$ Activities of daily living.

${ }^{1}$ Values refer to normal walking speed.

speed. Further descriptive values of selected gait parameters are shown in online supplementary table 1.

Figure 1 shows the means of selected gait parameters in the 5-year age groups during normal, fast and dualtask walking, respectively. With increasing age, a significant deterioration of physical performance was observed both in men and women for velocity, cadence and step length ( $p$ trend $<0.05$ ). The highest relative changes in gait performance across the five age groups occurred during fast speed (velocity: $23.7 \%$ for men, $21.4 \%$ for women; step length: $20.2 \%$ for men, $14.4 \%$ for women) and dual-task walking (velocity: $26.1 \%$ for men, $23.4 \%$ for women; step length: $19.7 \%$ for men, $12.6 \%$ for women).

A comparison of sex-specific means and $95 \%$ CIs between gait parameters in subjects with hip or knee endoprostheses and those without is given in tables 2 and 3 . Among women, significant differences between these two groups were observed during fast speed only. Women with hip or knee endoprostheses were $6.9 \%$ slower and had 3.1\% shorter step lengths than their healthy counterparts when given the task of walking fast. Among men, no such pattern was found. 


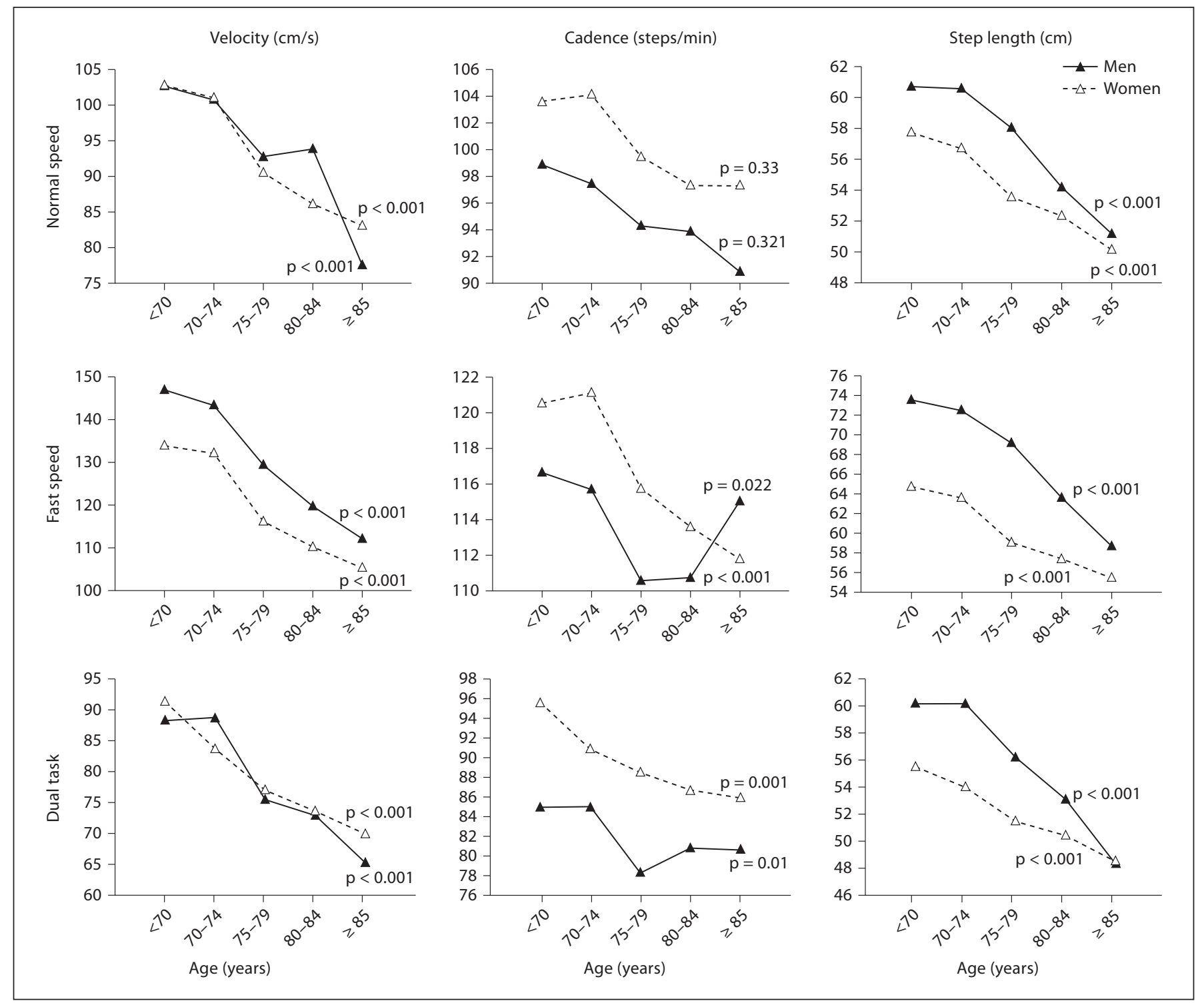

Fig. 1. Means for selected gait parameters during normal speed, fast speed and dual-task walking according to different age groups. Adjusted for height, weight, use of mobility aids, BMI, physical activity, cognitive status, arthritis, stroke, neurologic disease and eye disease. Normal speed (men/women): $<70$ years (100/98), $70-74$ years (108/107), $75-79$ years (111/109), $80-84$ years
(101/96), $\geq 85$ years $(34 / 42)$. Fast speed (men/women): $<70$ years (98/98), 70-74 years (107/106), 75-79 years (109/109), $80-84$ years (100/96), $\geq 85$ years (32/39). Dual-task walking (men/women): $<70$ years (99/98), 70-74 years (107/107), 75-79 years (108/108), $80-84$ years $(99 / 95)$, $\geq 85$ years $(30 / 39)$.
Table 4 depicts the differences between participants using a mobility aid and those not requiring a mobility aid. The results showed significant differences $(\mathrm{p}<0.05)$ between the two groups across all walking speeds for velocity, step length and cadence (except for slow speed in men). Among women, the greatest differences of relative performance when comparing the mobility aid group to their counterparts were marked during fast walking speed (velocity: 22.9\%; cadence: $14.5 \%$; step length: $12.6 \%)$. In contrast, among men, the weaker gait performance of mobility aid users cannot be ascribed to a particular gait task. However, the greatest decline in velocity (30.4\%) and cadence (18.5\%) was observed during dualtask walking. 
Table 2. Means ${ }^{1}$ and $95 \%$ CIs (in parentheses) for gait parameters according to participants with different types of endoprostheses among men

\begin{tabular}{|c|c|c|c|c|c|c|c|c|c|}
\hline & \multicolumn{3}{|c|}{ Hip endoprosthesis } & \multicolumn{3}{|c|}{ Knee endoprosthesis } & \multicolumn{3}{|c|}{ Hip or knee endoprosthesis ${ }^{2}$} \\
\hline \multicolumn{10}{|l|}{ Normal speed } \\
\hline Participants, $\mathrm{n}$ & 418 & 36 & & 433 & 21 & & 400 & 54 & \\
\hline Velocity, $\mathrm{cm} / \mathrm{s}$ & $\begin{array}{l}109.2 \\
(107.3-111.1)\end{array}$ & $\begin{array}{l}110.7 \\
(104.0-117.3)\end{array}$ & 0.688 & $\begin{array}{l}109.3 \\
(107.5-111.2)\end{array}$ & $\begin{array}{l}110.2 \\
(101.2-119.1)\end{array}$ & 0.854 & $\begin{array}{l}109.2 \\
(107.2-111.1)\end{array}$ & $\begin{array}{l}110.8 \\
(105.2-116.4)\end{array}$ & 0.586 \\
\hline Step length, cm & $\begin{array}{l}64.0 \\
(63.2-64.7)\end{array}$ & $\begin{array}{l}63.4 \\
(60.8-66.1)\end{array}$ & 0.714 & $\begin{array}{l}64.0 \\
(63.2-64.7)\end{array}$ & $\begin{array}{l}63.3 \\
(59.8-66.9)\end{array}$ & 0.752 & $\begin{array}{l}64.0 \\
(63.2-64.7)\end{array}$ & $\begin{array}{l}63.4 \\
(61.2-65.7)\end{array}$ & 0.668 \\
\hline \multicolumn{10}{|l|}{ Slow speed } \\
\hline Participants, $\mathrm{n}$ & 413 & 36 & & 428 & 21 & & 395 & 54 & \\
\hline Velocity, cm/s & $\begin{array}{l}58.2 \\
(56.5-60.0)\end{array}$ & $\begin{array}{l}63.4 \\
(57.3-70.0)\end{array}$ & 0.111 & $\begin{array}{l}58.6 \\
(56.8-60.3)\end{array}$ & $\begin{array}{l}60.5 \\
(52.3-68.8)\end{array}$ & 0.650 & $\begin{array}{l}58.1 \\
(56.3-59.9)\end{array}$ & $\begin{array}{l}62.7 \\
(57.5-67.8)\end{array}$ & 0.108 \\
\hline
\end{tabular}

\begin{tabular}{|c|c|c|c|c|c|c|c|c|c|}
\hline \multicolumn{10}{|l|}{ Fast speed } \\
\hline Participants, $\mathrm{n}$ & 411 & 35 & & 425 & 21 & & 393 & 53 & \\
\hline Velocity, cm/s & $\begin{array}{l}153.1 \\
(150.3-155.9)\end{array}$ & $\begin{array}{l}148.2 \\
(138.3-158.2)\end{array}$ & 0.363 & $\begin{array}{l}153.2 \\
(150.5-156.0)\end{array}$ & $\begin{array}{l}141.9 \\
(128.6-155.2)\end{array}$ & 0.106 & $\begin{array}{l}153.6 \\
(150.7-156.5)\end{array}$ & $\begin{array}{l}146.3 \\
(137.9-154.7)\end{array}$ & 0.113 \\
\hline Step length, $\mathrm{cm}$ & $\begin{array}{l}75.3 \\
(74.4-76.3)\end{array}$ & $\begin{array}{l}73.7 \\
(70.4-77.1)\end{array}$ & 0.379 & $\begin{array}{l}75.4 \\
(74.4-76.3)\end{array}$ & $\begin{array}{l}71.4 \\
(67.0-75.9)\end{array}$ & 0.096 & $\begin{array}{l}75.5 \\
(74.5-76.5)\end{array}$ & $\begin{array}{l}73.1 \\
(70.2-76.0)\end{array}$ & 0.124 \\
\hline
\end{tabular}

\begin{tabular}{|c|c|c|c|c|c|c|c|c|c|}
\hline \multicolumn{10}{|l|}{ Dual-task walking } \\
\hline Participants, $\mathrm{n}$ & 408 & 35 & & 422 & 21 & & 390 & 53 & \\
\hline Velocity, $\mathrm{cm} / \mathrm{s}$ & $\begin{array}{l}93.5 \\
(91.2-95.8)\end{array}$ & $\begin{array}{l}96.2 \\
(88.0-104.3)\end{array}$ & 0.532 & $\begin{array}{l}94.1 \\
(91.8-96.4)\end{array}$ & $\begin{array}{l}84.9 \\
(74.1-95.8)\end{array}$ & 0.108 & $\begin{array}{l}93.8 \\
(91.4-96.2)\end{array}$ & $\begin{array}{l}92.7 \\
(85.9-99.6)\end{array}$ & 0.779 \\
\hline Cadence, steps/min & $\begin{array}{l}89.7 \\
(88.3-91.1)\end{array}$ & $\begin{array}{l}92.2 \\
(87.1-97.2)\end{array}$ & 0.352 & $\begin{array}{l}90.1 \\
(88.7-91.5)\end{array}$ & $\begin{array}{l}86.4 \\
(79.6-93.1)\end{array}$ & 0.296 & $\begin{array}{l}89.8 \\
(88.3-91.3)\end{array}$ & $\begin{array}{l}90.5 \\
(86.3-94.8)\end{array}$ & 0.752 \\
\hline Step length, cm & $\begin{array}{l}62.0 \\
(61.1-62.8)\end{array}$ & $\begin{array}{l}62.3 \\
(59.2-65.5)\end{array}$ & 0.813 & $\begin{array}{l}62.2 \\
(61.3-63.0)\end{array}$ & $\begin{array}{l}58.2 \\
(54.1-62.4)\end{array}$ & 0.076 & $\begin{array}{l}62.1 \\
(61.2-63.0)\end{array}$ & $\begin{array}{l}61.0 \\
(58.4-63.7)\end{array}$ & 0.458 \\
\hline
\end{tabular}

${ }^{1}$ Adjusted for age, height, weight, use of mobility aids, physical activity level, BMI, cognitive status, arthritis, stroke, neurological disease and eye disease. ${ }^{2}$ Includes participants who had both a hip and a knee endoprosthesis.

\section{Discussion}

In this cross-sectional representative study investigating four different walking conditions, we found an ageand mobility aid-associated decline in gait performance which was most notable during fast and dual-task walking. Furthermore, we observed significantly weaker performances in fast speed among female participants with knee or hip endoprostheses. To our knowledge, this is the largest population-based study assessing gait parameters by the validated GAITRite walkway system in older adults and specifically highlighting different walking conditions taking account of endoprostheses and mobility aid users.

\section{Age-Associated Gait Changes}

A variety of gait parameters (velocity, cadence and step length) were subject to age-related changes across the walking tasks in both men and women. These findings are in accordance with another study [7] reporting 
Table 3. Means ${ }^{1}$ and $95 \%$ CIs (in parentheses) for gait parameters according to participants with different types of endoprostheses among women

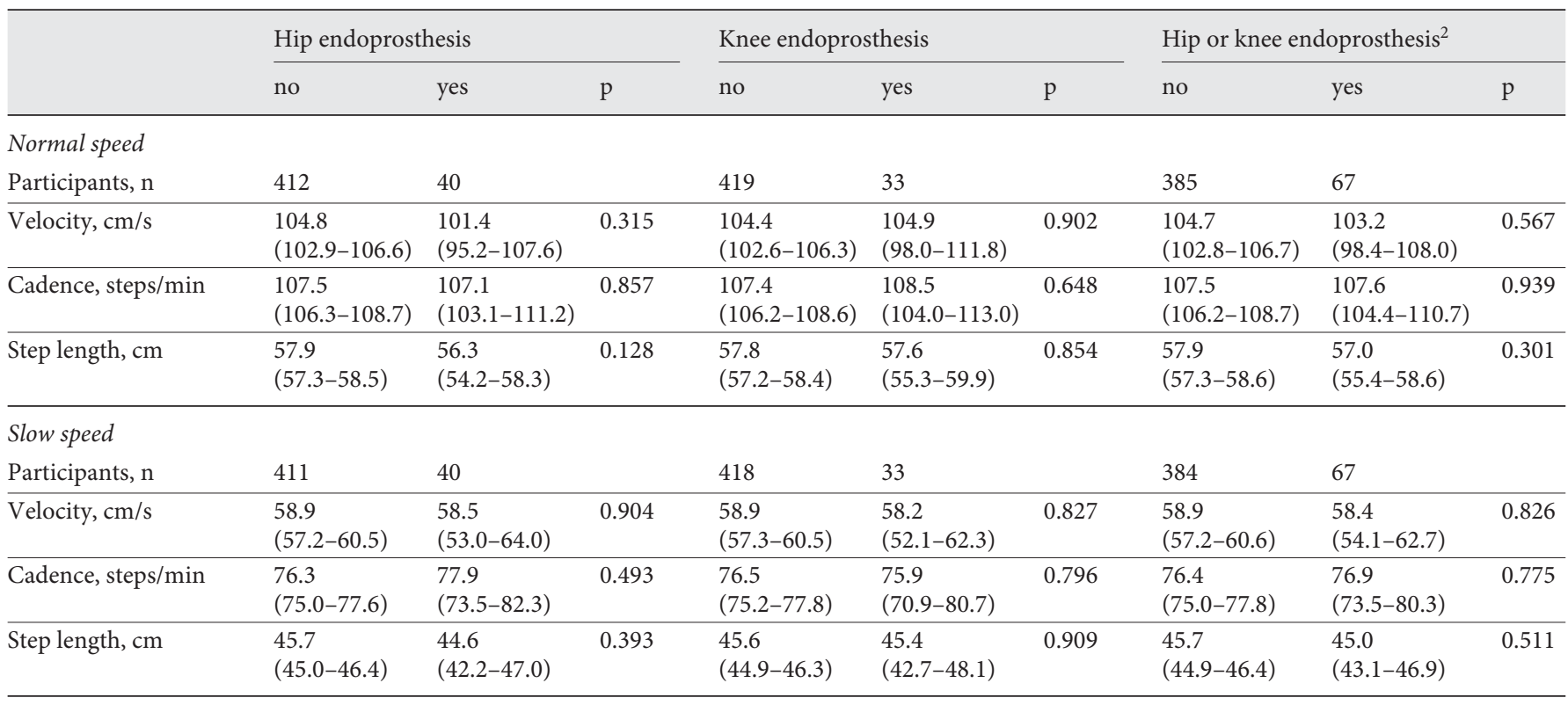

Fast speed

\begin{tabular}{|c|c|c|c|c|c|c|c|c|c|}
\hline Participants, $n$ & 408 & 40 & & 415 & 33 & & 381 & 67 & \\
\hline Velocity, $\mathrm{cm} / \mathrm{s}$ & $\begin{array}{l}136.5 \\
(134.0-138.9)\end{array}$ & $\begin{array}{l}127.3 \\
(119.2-135.4)\end{array}$ & 0.036 & $\begin{array}{l}136.3 \\
(133.9-138.7)\end{array}$ & $\begin{array}{l}127.9 \\
(118.9-136.9)\end{array}$ & 0.080 & $\begin{array}{l}137.1 \\
(134.6-139.6)\end{array}$ & $\begin{array}{l}127.6 \\
(121.3-133.8)\end{array}$ & 0.007 \\
\hline Cadence, steps/min & $\begin{array}{l}125.5 \\
(124.0-127.0)\end{array}$ & $\begin{array}{l}122.3 \\
(117.3-127.4)\end{array}$ & 0.245 & $\begin{array}{l}125.7 \\
(124.2-127.2)\end{array}$ & $\begin{array}{l}119.2 \\
(113.7-124.8)\end{array}$ & 0.030 & $\begin{array}{l}126.0 \\
(124.4-127.6)\end{array}$ & $\begin{array}{l}120.7 \\
(116.8-124.6)\end{array}$ & 0.015 \\
\hline Step length, cm & $\begin{array}{l}64.6 \\
(63.9-65.4)\end{array}$ & $\begin{array}{l}61.6 \\
(59.3-64.0)\end{array}$ & 0.018 & $\begin{array}{l}64.4 \\
(63.7-65.1)\end{array}$ & $\begin{array}{l}63.7 \\
(61.1-66.3)\end{array}$ & 0.602 & $\begin{array}{l}64.7 \\
(63.9-65.4)\end{array}$ & $\begin{array}{l}62.7 \\
(60.8-64.5)\end{array}$ & 0.049 \\
\hline
\end{tabular}

Dual-task walking

\begin{tabular}{lllllllll} 
Participants, $\mathrm{n}$ & 407 & 40 & & 414 & 33 & 380 & 67 \\
\hline Velocity, cm/s & 87.2 & 86.1 & 0.778 & 87.3 & 84.1 & 0.455 & 87.2 & 86.2 \\
& $(85.0-89.3)$ & $(78.9-93.3)$ & & $(85.2-89.5)$ & $(76.2-92.1)$ & & $(85.0-89.5)$ & $(80.6-91.7)$ \\
\hline Cadence, steps/min & 93.8 & 93.9 & 0.969 & 93.9 & 91.9 & 0.528 & 93.8 & 93.735 \\
& $(92.1-95.4)$ & $(88.4-99.3)$ & & $(92.3-95.6)$ & $(85.8-98.0)$ & & $(92.1-95.5)$ & $(89.3-97.8)$ \\
\hline Step length, cm & 55.1 & 54.5 & 0.630 & 55.1 & 54.5 & 0.655 & 55.1 & 5.898 \\
& $(54.4-55.8)$ & $(52.2-56.8)$ & & $(54.4-55.8)$ & $(51.9-57.0)$ & & $(54.4-55.8)$ & $(53.0-56.6)$ \\
\hline
\end{tabular}

${ }^{1}$ Adjusted for age, height, weight, use of mobility aids, physical activity level, BMI, cognitive status, arthritis, stroke, neurological disease and eye disease. ${ }^{2}$ Includes participants who had both a hip and a knee endoprosthesis.

a significant sex-specific relation between age and the gait variables speed, step length, step width and double support in men and women as well as cadence in women. Interestingly, in both sexes, the highest relative change for step length was found during fast walking while the highest change in velocity was observed during the dual-task test. This finding suggests that agerelated features of the gait pattern depend on the specific demands of a walking test the subject has to cope with.
Overall, the conditions 'fast walking' as well as 'dualtask walking' seem to be most sensitive in the detection of age-associated gait alterations.

\section{Gait Alterations in Subjects with Endoprostheses and} in Need of Mobility Aids

Previous studies assessing gait variables with an electronic walkway mat often did not take account of the impact of endoprostheses although gait patterns have been described to be significantly affected in those pa- 
Table 4. Means ${ }^{1}$ and $95 \%$ CIs (in parentheses) for gait parameters according to persons with and without mobility aids

\begin{tabular}{|c|c|c|c|c|c|c|}
\hline & without mobility aid & with mobility aid & $\mathrm{p}$ & without mobility aid & with mobility aid & $\mathrm{p}$ \\
\hline Velocity, $\mathrm{cm} / \mathrm{s}$ & $110.4(108.6-112.3)$ & $78.0(67.5-88.6)$ & $<0.001$ & $106.1(104.3-107.9)$ & $82.5(75.8-89.6)$ & $<0.001$ \\
\hline Cadence, steps/min & $102.6(101.6-103.7)$ & $88.7(82.6-94.7)$ & $<0.001$ & $108.5(107.3-109.7)$ & $93.2(88.6-97.9)$ & $<0.001$ \\
\hline \multicolumn{7}{|l|}{ Slow speed } \\
\hline Participants, $\mathrm{n}$ & 437 & 12 & & 420 & 31 & \\
\hline Velocity, $\mathrm{cm} / \mathrm{s}$ & $59.0(57.3-60.7)$ & $45.9(35.1-56.7)$ & 0.020 & $59.5(57.9-61.2)$ & $49.6(43.4-55.9)$ & 0.003 \\
\hline Cadence, steps/min & $73.0(71.7-74.2)$ & $67.7(59.9-75.6)$ & 0.196 & $76.9(75.6-78.2)$ & $70.8(65.8-75.9)$ & 0.025 \\
\hline Step length, $\mathrm{cm}$ & $47.8(47.0-48.6)$ & $40.3(35.1-45.5)$ & 0.006 & $45.9(45.2-46.6)$ & $41.4(38.6-44.1)$ & 0.002 \\
\hline \multicolumn{7}{|l|}{ Fast speed } \\
\hline Step length, cm & $75.5(74.6-76.4)$ & $62.6(56.4-68.7)$ & $<0.001$ & $64.9(64.2-65.6)$ & $56.8(54.0-59.5)$ & $<0.001$ \\
\hline \multicolumn{7}{|l|}{ Dual-task walking } \\
\hline Participants, $\mathrm{n}$ & 432 & 11 & & 418 & 29 & \\
\hline Velocity, $\mathrm{cm} / \mathrm{s}$ & $94.4(92.2-96.6)$ & $65.7(51.0-80.5)$ & $<0.001$ & $88.0(85.9-90.1)$ & $73.8(65.4-82.2)$ & 0.001 \\
\hline Cadence, steps/min & $90.3(88.9-91.7)$ & $73.6(64.4-82.7)$ & $<0.001$ & 94.3 (92.7-95.9) & $86.2(79.8-92.6)$ & 0.017 \\
\hline Step length, cm & $62.3(61.4-63.1)$ & $51.4(45.7-57.1)$ & $<0.001$ & $55.4(54.7-56.1)$ & $49.8(47.1-52.4)$ & $<0.001$ \\
\hline
\end{tabular}

tients [11-13], and only very few studies have used the GAITRite system to describe gait patterns among persons with knee or hip endoprostheses [21, 22]. We found that women with hip endoprostheses had a significantly reduced physical performance during fast walking as indicated by the gait parameters velocity and step length. These findings are somewhat different from a case-control study by Guedes et al. [21], in which 23 subjects with hip arthroplasties differed significantly from their 23 controls in velocity on all walking tasks (usual, fast, slow and dual-task), but not in cadence. However, these data might be difficult to compare as the study by Guedes et al. was based on a convenience sample and did not analyze sex-specific differences.

The mobility aid users in our study were significantly slower, with fewer steps per minute and smaller steps compared to the nonuser group in all gait speeds or tasks. It may seem obvious to assume that the group not using mobility aids would perform better as they are mainly considered to be healthier or less frail. However, an additional reason for the difference between those groups might be that the use of these mobility aids usually will alter the gait pattern as their permanent users seem to seek enhanced balance rather than mobility [23].

Major Implications of Gait Changes among the Elderly

Everyday gait tasks such as walking while performing cognitive tasks have been suggested to increase the risk of falling among the aged $[24,25]$ and its assessment is therefore highly important to detect fall-prone older adults at an early stage. Understanding the gait patterns of older people is crucial to prevent potential falls, as falls among individuals aged $\geq 65$ years are an important indication of chronic morbidity and a major cause of accidental deaths [26]. An unsteady gait has been established as one of the factors contributing to a higher risk of falls among older persons [27]. In addition, poor performance during fast walking has been described as an independent predictor of loss of cognitive function [28]. Other subtasks such as gait termination, turning or crossing of obstacles have also been the subject of gait analyses. However, it has been equivocal whether these tasks may be 
accomplished much better in the clinical setting where the participant is able to prepare for certain gait tasks compared to unanticipated gait tasks in the real world [29]. Our study participants were therefore given instructions regarding walking speeds and simultaneous cognitive tasks at short notice, namely directly before the upcoming next walk.

\section{Strengths and Limitations}

The strengths of this study include its populationbased representative design and the careful, high-quality assessment of gait parameters by means of the validated GAITRite walkway system. In addition, the large sample size guaranteed enough statistical power for the regression analyses. Furthermore, the three different walking speeds as well as the dual-task walking reflect typical everyday life situations and the description of gait parameters within these four walking tasks thus provides valuable information on gait performance in everyday life. Careful evaluation of important covariates such as cognitive status or neurological diseases in the KORA-Age study allowed for the adjustment of risk factors related to gait performance.

One limitation of our study may be the cross-sectional design that hampers causal inference given also that only mobile persons may have visited the examination center. A follow-up study of KORA-Age will likely provide additional information on gait changes during aging. Furthermore, the assessment of gait parameters was part of a series of examinations conducted in the KORA Study Center in Augsburg, which, on average, lasted $2.5 \mathrm{~h}$. This examination time may have tired our participants and could have led to weaker physical gait performances. However, the gait velocity for normal speed was within the range of published data for this age group.

\section{Conclusion}

According to our results in a large population-based study of 907 older adults, a decline in gait performance was most notable in the gait tasks 'fast speed' and 'dualtask walking' when analyzing persons not using mobility aids versus persons using mobility aids or persons fitted with endoprostheses and persons without endoprostheses, or when comparing five different age groups.

Since large sample sizes for the description of age- and sex-specific gait parameters are scarce, our data greatly contribute to obtaining reference values for future studies in this field.

\section{Acknowledgements}

This study was funded by the German Research Foundation (Deutsche Forschungsgemeinschaft) (GR 3608/1-1). The KORA research platform was initiated and financed by the Helmholtz Zentrum München, German Research Center for Environmental Health, which is funded by the German Federal Ministry of Education and Research and by the State of Bavaria. The KORA-Age project was financed by the German Federal Ministry of Education and Research (BMBF FKZ 01ET0713) as part of the Health in Old Age program. We thank all members of the Department of Epidemiology II of the Helmholtz Zentrum München and the field staff in Augsburg who were involved in the planning and conduct of the MONICA/KORA Augsburg. Finally, we express our appreciation to all study participants.

\section{Disclosure Statement}

The authors declare they have no conflict of interest.

\section{References}

1 Rowe JW, Kahn RL: Successful aging. Gerontologist 1997;37:433-440.

- Strawbridge WJ, Wallhagen MI, Cohen RD: Successful aging and well-being: self-rated compared with Rowe and Kahn. Gerontologist 2002;42:727-733.

-3 Alexander NB, Goldberg A: Gait disorders: search for multiple causes. Cleve Clin J Med 2005;72:586, 589-590, 592-584 passim.

-4 Seeman TE, Charpentier PA, Berkman LF, Tinetti ME, Guralnik JM, Albert M, Blazer $\mathrm{D}$, Rowe JW: Predicting changes in physical performance in a high-functioning elderly cohort: MacArthur studies of successful aging. J Gerontol 1994;49:M97-M108.

5 Beauchet O, Allali G, Annweiler C, Bridenbaugh S, Assal F, Kressig RW, Herrmann FR: Gait variability among healthy adults: low and high stride-to-stride variability are both a reflection of gait stability. Gerontology 2009;55:702-706.

6 Brach JS, Studenski S, Perera S, Van Swearingen JM, Newman AB: Stance time and step width variability have unique contributing impairments in older persons. Gait Posture 2008;27:431-439.
Callisaya ML, Blizzard L, Schmidt MD, McGinley JL, Srikanth VK: Sex modifies the relationship between age and gait: a population-based study of older adults. J Gerontol A Biol Sci Med Sci 2008;63:165-170.

$>$ Callisaya ML, Blizzard L, Schmidt MD, McGinley JL, Srikanth VK: Ageing and gait variability - a population-based study of older people. Age Ageing 2010;39:191-197.

-9 Dusing SC, Thorpe DE: A normative sample of temporal and spatial gait parameters in children using the GAITRite electronic walkway. Gait Posture 2007;25:135-139. 
10 Kressig RW, Beauchet O: Guidelines for clinical applications of spatio-temporal gait analysis in older adults. Aging Clin Exp Res 2006;18:174-176.

-11 Bennett D, Humphreys L, O’Brien S, Kelly C, Orr JF, Beverland DE: Gait kinematics of age-stratified hip replacement patients - a large scale, long-term follow-up study. Gait Posture 2008;28:194-200.

12 Milner CE: Is gait normal after total knee arthroplasty? Systematic review of the literature. J Orthop Sci 2009;14:114-120.

13 Tanaka R, Shigematsu M, Motooka T, Mawatari M, Hotokebuchi T: Factors influencing the improvement of gait ability after total hip arthroplasty. J Arthroplasty 2010;25:982985.

14 Lacruz ME, Emeny RT, Bickel H, Cramer B, Kurz A, Bidlingmaier M, Huber D, Klug G, Peters A, Ladwig KH: Mental health in the aged: prevalence, covariates and related neuroendocrine, cardiovascular and inflammatory factors of successful aging. BMC Med Res Methodol 2010;10:36.

15 McDonough AL, Batavia M, Chen FC, Kwon S, Ziai J: The validity and reliability of the GAITRite system's measurements: a preliminary evaluation. Arch Phys Med Rehabil 2001;82:419-425.
16 Webster KE, Wittwer JE, Feller JA: Validity of the GAITRite walkway system for the measurement of averaged and individual step parameters of gait. Gait Posture 2005; 22:317-321.

17 CIR Systems Inc: GAITRite Operating Manual. Haverton, CIR Systems, 2007.

18 CIR Systems Inc: The GAITRite electronic walkway measurements and definitions. Haverton, CIR Systems, 2006.

19 Gallo JJ, Breitner JC: Alzheimer's disease in the NAS-NRC registry of aging twin veterans. IV. Performance characteristics of a two-stage telephone screening procedure for Alzheimer's dementia. Psychol Med 1995;25: 1211-1219.

20 Knopman DS, Roberts RO, Geda YE, Pankratz VS, Christianson TJ, Petersen RC, Rocca WA: Validation of the telephone interview for cognitive status-modified in subjects with normal cognition, mild cognitive impairment, or dementia. Neuroepidemiology 2010;34:34-42.

-21 Guedes RC, Dias JM, Dias RC, Borges VS, Lustosa LP, Rosa NM: Total hip arthroplasty in the elderly: impact on functional performance. Rev Bras Fisioter 2011;15:123-130.

22 Webster KE, Wittwer JE, Feller JA: Quantitative gait analysis after medial unicompartmental knee arthroplasty for osteoarthritis. J Arthroplasty 2003;18:751-759.
23 Liu HH, McGee M, Wang W, Persson M: Comparison of gait characteristics between older rolling walker users and older potential walker users. Arch Gerontol Geriatr 2009; 48:276-280.

24 Beauchet O, Annweiler C, Dubost V, Allali G, Kressig RW, Bridenbaugh S, Berrut G, Assal F, Herrmann FR: Stops walking when talking: a predictor of falls in older adults? Eur J Neurol 2009;16:786-795.

25 Lundin-Olsson L, Nyberg L, Gustafson Y: 'Stops walking when talking' as a predictor of falls in elderly people. Lancet 1997;349: 617.

26 World Health Organization: WHO global report on falls prevention in older age. Geneva, World Health Organization, 2008.

27 Rubenstein LZ: Falls in older people: epidemiology, risk factors and strategies for prevention. Age Ageing 2006;35(suppl 2):ii37ii41.

28 Deshpande N, Metter EJ, Bandinelli S, Guralnik J, Ferrucci L: Gait speed under varied challenges and cognitive decline in older persons: a prospective study. Age Ageing 2009;38:509-514.

29 Sparrow WA, Tirosh O: Gait termination: a review of experimental methods and the effects of ageing and gait pathologies. Gait Posture $2005 ; 22: 362-371$ 